\title{
Theologíe
}

\section{Des alten $\mathbb{C e} f \operatorname{taments}$}

$\mathfrak{b} \mathfrak{a}$

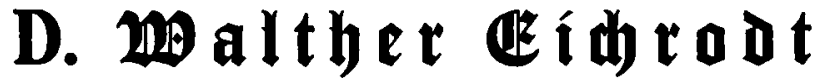

Profeffor an der Zuniberfitát $2 B$ afel

\author{
Teil 1 \\ Gott und 2 olk
}

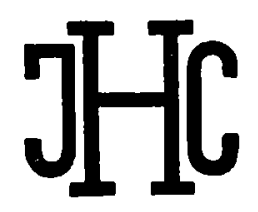

1 e i p : i g

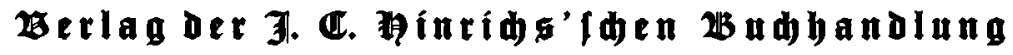




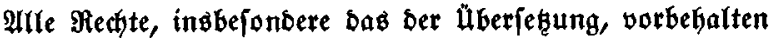

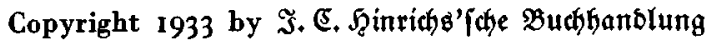


Der hodhärdigen zheologifden Fafultät

ber Fribericolatexandina in Erlangen

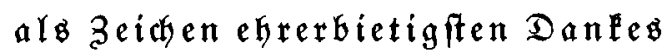

für bie $\mathfrak{B e r l e i f u n g ~ b e r ~} \mathfrak{B}$ ürde eines Doftor der zheologie 
